\title{
Surface modifications and deuterium depth profiles in molybdenum irradiated with low-energy D ions
}

\author{
V.Kh. Alimov ${ }^{*}$, J. Roth, S. Lindig, \\ Max-Planck-Institut für Plasmaphysik, EURATOM Association, Boltzmannstrasse 2, \\ D-85748 Garching, Germany
}

\begin{abstract}
Depth profiles of deuterium trapped in single crystal Mo, polycrystalline Mo, and molybdenum trioxide film on polycrystalline Mo irradiated with $200 \mathrm{eV}$ D ions have been measured up to a depth of $8 \mu \mathrm{m}$ using the $\mathrm{D}\left({ }^{3} \mathrm{He}, \mathrm{p}\right){ }^{4} \mathrm{He}$ nuclear reaction at a ${ }^{3} \mathrm{He}$ energy varied from 0.69 to $4.0 \mathrm{MeV}$. For the $\mathrm{D}$ ion irradiation at $323 \mathrm{~K}$ to the highest ion fluence of $5 \times 10^{24} \mathrm{D} / \mathrm{m}^{2}$, the D concentration decreases from several at.\% in the near-surface layer to bulk values below $10^{-4}$ at. $\%$ for single crystal Mo and about $10^{-2}$ at. $\%$ for polycrystalline Mo. The maximum D concentration in molybdenum trioxide film differs little in value from that for polycrystalline Mo. Blister formation at high fluences is observed for polycrystalline Mo and molybdenum trioxide film, but not for single crystal Mo. As the irradiation temperature increases from 323 to $493 \mathrm{~K}$, the D retention in the polycrystalline Mo decreases from about $3 \times 10^{21}$ down to about $2 \times 10^{18} \mathrm{D} / \mathrm{m}^{2}$.
\end{abstract}

PACS: 61.80.Jh

JNM keywords: Hydrogen and Hydrides; Ion Irradiation; Plasma-Materials Interaction; Molybdenum, Molybdenum Alloys and Compounds.

* Corresponding author. Tel.: +81 29282 6452; fax: +81 292825917.

E-mail address: vkahome@mail.ru (V.Kh. Alimov).

${ }^{1}$ Guest Scientist from the Institute of Physical Chemistry and Electrochemistry, Russian Academy of Sciences, Moscow, Russia. 


\section{Introduction}

Molybdenum (Mo) is one of several refractory metals being considered for use in fusion devices $[1,2,3]$. As a plasma-facing material, Mo will be subject to intense fluxes of energetic deuterium and tritium ions and neutrals. This implantation process leads to concerns about tritium inventories after long-term deuterium-tritium plasma exposure. There are numerous publications devoted to hydrogen inventory in molybdenum materials irradiated with hydrogen isotope ions at temperatures in the range from 160 to $887 \mathrm{~K}$ [4, 5, $6,7,8,9,10,11,12,13,14]$. In a majority of these studies Mo was irradiated with hydrogen isotope ions at energies above $1 \mathrm{keV}$. Only publications [8, 13, 14] present reviews of results on hydrogen retention after low-energy (in the range several hundreds $\mathrm{eV}$ ) plasma exposure. While information about the total amount of hydrogen retained in Mo materials and about hydrogen detrapping energies can be obtained from thermal desorption measurements, measurements of hydrogen depth profiles can give detailed information about the depth distribution of defects which are responsible for hydrogen trapping, and therefore, can help to understand the mechanisms of hydrogen-material interactions. The deuterium concentration in $25 \mu \mathrm{m}$ Mo foils exposed to a high-flux $100 \mathrm{eV}$ D plasma to a fluence of $1.7 \times 10^{24} \mathrm{D} / \mathrm{m}^{2}$ at $400 \mathrm{~K}$, as measured by Wright et al. with ion beam analysis [14], changed from 0.8 to 0.1 at.\% at depths of from 0 to $5 \mu \mathrm{m}$.

In the present investigation we compare depth profiles of deuterium trapped within the $7 \mu \mathrm{m}$ thick sub-surface layer of different molybdenum materials irradiated with $200 \mathrm{eV}$ $\mathrm{D}$ ions. The $\mathrm{D}\left({ }^{3} \mathrm{He}, \mathrm{p}\right){ }^{4} \mathrm{He}$ nuclear reaction at different ${ }^{3} \mathrm{He}$ energies was used for quantitative depth profiling.

\section{Experimental}

Three types of Mo samples were investigated:

(i) Single crystal Mo of 99.9 at.\% purity with 1-5 mm macro-crystallite size, produced by double electron-beam zone melting at the State Institute of Rare Metals, Moscow. The samples were cut from a Mo rod by spark cutting and were $1 \mathrm{~mm}$ in thickness. The sample surface was parallel to the (100) crystallographic plane. 
(ii) Polycrystalline, reduced-rolled Mo foil of 99.6 at.\% purity, $0.5 \mathrm{~mm}$ in thickness, produced by the powder-metallurgy process (Plansee Aktiengesellschaft, Austria). The grain size was estimated to be in the range of $1-5 \mu \mathrm{m}$.

The single crystalline and polycrystalline Mo samples were mechanically and electrochemically polished.

(iii) Sandwich of polycrystalline $\mathrm{Mo}$ with $\mathrm{a} \mathrm{MoO}_{3}$ film deposited in a commercial magnetron device by RF sputtering of a Mo cathode in oxygen-argon atmosphere at a pressure of $0.66 \mathrm{~Pa}$ controlled by the $\mathrm{O}_{2}$ and $\mathrm{Ar}$ influx $\left(1.3 \times 10^{-7}\right.$ and $1.7 \times 10^{-7} \mathrm{~m}^{3} / \mathrm{s}$, respectively). The film growth rate was determined from the thickness of the films deposited specially on glass and (100) silicon substrates and the deposition time. The film thickness was measured by a surface profiler (Alpha-Step 200, TENCOR Instruments) using the step between film and substrate. Based on the film growth rate, the thickness of the $\mathrm{MoO}_{3}$ films grown on polycrystalline Mo was estimated to be about $115 \mathrm{~nm}$.

The concentration of oxygen in the deposited $\mathrm{MoO}_{3}$ film before and after irradiation with $\mathrm{D}$ ions was determined by Rutherford backscattering analysis.

The irradiation with $600 \mathrm{eV} \mathrm{D}_{3}{ }^{+}(200 \mathrm{eV} / \mathrm{D})$ was performed in a vacuum chamber connected to a high-current ion source [15] at normal ion incidence. For better ion source performance, a $3600 \mathrm{eV} \mathrm{D}_{3}{ }^{+}$ion beam was extracted from the ion source, magnetically analyzed, and decelerated in front of the samples by a positive target bias of $3000 \mathrm{~V}$ to achieve $600 \mathrm{eV} \mathrm{D}_{3}{ }^{+}$. The ion flux was $(3.4 \pm 0.7) \times 10^{19} \mathrm{D} / \mathrm{m}^{2} \mathrm{~s}$ and due to the irradiation the sample was heated to $323 \mathrm{~K}$. By electron bombardment from the rear the irradiation temperature, $T_{\text {irr }}$, could be varied from 323 to $493 \mathrm{~K}$. The sample temperature was measured with an error of $\pm 20 \mathrm{~K}$ by means of an infrared pyrometer placed outside the chamber.

The D concentration within the near-surface layer (at depths of up to $\sim 0.5 \mu \mathrm{m}$ ) was measured by means of the $\mathrm{D}\left({ }^{3} \mathrm{He}, \alpha\right) \mathrm{H}$ reaction at a ${ }^{3} \mathrm{He}$ energy of $0.69 \mathrm{MeV}$, with the $\alpha$ particles being energy-analyzed with a small-angle surface barrier detector at the laboratory scattering angle of $102^{\circ}$. The $\alpha$ spectrum was transformed into a D depth profile using the program SIMNRA [16].

To determine the $\mathrm{D}$ concentration at larger depths, an analyzing beam of ${ }^{3} \mathrm{He}$ ions with energies varied from 0.69 to $4 \mathrm{MeV}$ was used. The protons from the $\mathrm{D}\left({ }^{3} \mathrm{He}, \mathrm{p}\right)^{4} \mathrm{He}$ nuclear reaction were counted using a wide-angle proton detector placed at an angle of $135^{\circ}$. In order to determine the $\mathrm{D}$ concentration profile in deeper layers, the computer 
program SIMNRA was used for the deconvolution of the proton yields measured at different ${ }^{3} \mathrm{He}$ ion energies. A deuterium depth distribution was assumed taking into account the near-surface depth profile obtained from the $\alpha$ particle spectrum, and the integral proton yield as a function of incident ${ }^{3} \mathrm{He}$ energy was calculated. The form of the D depth profile was then varied using an iterative technique until the calculated curve matched the measured proton yields [17].

The surface morphology of the ion irradiated Mo samples was investigated by scanning electron microscopy (SEM).

\section{Results and discussion}

Just as for tungsten $[18,19]$, the depth at which deuterium is retained in molybdenum irradiated with $200 \mathrm{eV} \mathrm{D}$ ions can be tentatively divided into three zones: (i) the nearsurface layer (up to a depth of $0.2-0.5 \mu \mathrm{m}$ ), (ii) a sub-surface layer (from about 0.5 to about $8 \mu \mathrm{m}$ ), and (iii) the bulk $(>8 \mu \mathrm{m})$. However, in the present experiments the $\mathrm{D}$ concentration was determined only to a depth of $8 \mu \mathrm{m}$, therefore the D concentration in the bulk can only be estimated.

The comparison of deuterium depth profiles in Mo single crystal and polycrystalline Mo irradiated at $323 \mathrm{~K}$ to the same ion fluence (Fig. 1) shows clearly the influence of the material structure on $\mathrm{D}$ retention. At the lowest fluence of $5 \times 10^{22} \mathrm{D} / \mathrm{m}^{2}$, the $\mathrm{D}$ depth profiles in the single crystal and polycrystalline Mo are characterized by a sharp nearsurface concentration maximum, and beginning from a depth of $0.2-0.5 \mu \mathrm{m}$, a decreasing concentration tail into the bulk. However, in single crystal Mo the near-surface concentration maximum is about $6 \times 10^{-2}$ at. $\%$ and the concentration in the sub-surface layer and the bulk is below $10^{-4}$ at.\% (Fig. $1 \mathrm{a}$ ), whereas in polycrystalline Mo these concentrations are about 3 at.\% and more than $10^{-3}$ at.\%, respectively (Fig. 1 b). As the fluence increases, the near-surface D concentration in the Mo single crystal increases significantly reaching 6-7 at.\% at a fluence of $5 \times 10^{24} \mathrm{D} / \mathrm{m}^{2}$, whereas the D concentration at depths greater than $2 \mu \mathrm{m}$ remains practically unchanged (Fig. $1 \mathrm{a})^{*}$. In the polycrystalline Mo, the near-surface D concentration rises slightly as the fluence increases, but the D

\footnotetext{
*) For single crystal Mo irradiated to a fluence of $5 \times 10^{24} \mathrm{D} / \mathrm{m}^{2}$, because of relatively high $\mathrm{D}$ concentration in the near-surface layer, the $\mathrm{D}$ concentration was not determined at depths greater than $2 \mu \mathrm{m}$. However, there is good reason to believe that the D concentration at these depths is below $10^{-3}$ at. $\%$.
} 
concentration in the sub-surface layer increases significantly. At the maximum fluence of $5 \times 10^{24} \mathrm{D} / \mathrm{m}^{2}$, the D profile in the polycrystalline Mo demonstrates, in addition to the nearsurface maximum, a relatively high D concentration (about 0.1 at.\%) at depths of 2 to $4 \mu \mathrm{m}$ (Fig. 1 b).

At $T_{\text {irr }}=323 \mathrm{~K}$, individual blisters with size (diameter) of $0.5-1 \mu \mathrm{m}$ begin to form on the surface of the polycrystalline Mo at a fluence of $5 \times 10^{23} \mathrm{D} / \mathrm{m}^{2}$. As the ion fluence increases, the blisters grow in size reaching 5-20 $\mu \mathrm{m}$ at a fluence of $5 \times 10^{24} \mathrm{D} / \mathrm{m}^{2}$ (Fig. 2 a). We note that no blisters appeared on the surface of the Mo single crystal irradiated at $323 \mathrm{~K}$ with $200 \mathrm{eV}$ D ions to fluences in the range from $1 \times 10^{22}$ to $1 \times 10^{24} \mathrm{D} / \mathrm{m}^{2}$ (not shown in Fig. 2).

Deuterium profiles in the $\mathrm{MoO}_{3} /$ polycrystalline Mo sandwich irradiated at $323 \mathrm{~K}$ with $200 \mathrm{eV}$ D ions to different fluences (Fig. 4) are characterized by relatively high D concentration in the molybdenum trioxide film (from 1 to 4 at.\% depending on the ion fluence) and low D concentration in the Mo matrix (about $10^{-2}$ at.\%) decreasing with depth. The Mo trioxide film gets thinner as the ion fluence increases and disappeares at a fluence of $5 \times 10^{24} \mathrm{D} / \mathrm{m}^{2}$ (Fig. 3, insert).

A wealth of blisters of size $0.2-1 \mu \mathrm{m}$ is formed on the surface of the $\mathrm{MoO}_{3} /$ polycrystalline Mo sandwich even at a fluence of $5 \times 10^{22} \mathrm{D} / \mathrm{m}^{2}$ (Fig. 2 b). As the trioxide film becomes thinner with increasing fluence, the dome of the blisters becomes lower though the number of blisters remains practically unchanged. Removal of the trioxide film by ion sputtering leads to the disappearance of blisters.

Increasing the irradiation temperature of polycrystalline Mo from 323 to $393 \mathrm{~K}$ leads to a significant decrease of the $\mathrm{D}$ concentration, whereas further temperature increase to $T_{\text {irr }}=493 \mathrm{~K}$ reduces the D concentration to a smaller extent (Fig. 4).

The retention of D integrated up to a depth of $8 \mu \mathrm{m}$ is shown in Fig. 5 for the three different materials. The integrated amount of retained D in the Mo single crystal irradiated with $200 \mathrm{eV} \mathrm{D}$ ions at $323 \mathrm{~K}$ demonstrates a more pronounced fluence dependence than observed for the polycrystalline $\mathrm{Mo}$ and the $115 \mathrm{~nm} \mathrm{MoO} /$ polycrystalline Mo sandwich (Fig. 5). For fluences in the range from $5 \times 10^{22}$ to about $1 \times 10^{24} \mathrm{D} / \mathrm{m}^{2}$, the highest $\mathrm{D}$ retention is observed for the $\mathrm{MoO}_{3} /$ polycrystalline Mo sandwich. However, as the ion fluence further increases the $\mathrm{D}$ retention in the sandwich slightly decreases due to sputtering of the trioxide film. At the highest fluence of $5 \times 10^{24} \mathrm{D} / \mathrm{m}^{2}$ the retention in all three materials reaches similar values around $2 \times 10^{20} \mathrm{D} / \mathrm{m}^{2}$. Note that the fluence 
dependences of D retention in polycrystalline Mo and W [18] are very similar (within uncertainties of measurements).

As the irradiation temperature increases from 323 to $493 \mathrm{~K}$, the D retention in the polycrystalline $\mathrm{W}$, as calculated from the integral of the $\mathrm{D}$ depth profiles measured up to a depth of $8 \mu \mathrm{m}$, decreases from about $3 \times 10^{21}$ to about $2 \times 10^{18} \mathrm{D} / \mathrm{m}^{2}$ (Fig. 5).

For tungsten implanted with D ions at energies below the displacement threshold, the mechanism of plastic deformation due to deuterium super-saturation has been considered for formation of trapping sites for deuterium [18, 19, 20]. During D ion irradiation or D plasma exposure, the $\mathrm{D}$ concentration in the implantation zone greatly exceeds the solubility limit and stresses the matrix lattice until plastic deformation occurs to alleviate these tensions. This deformation is assumed to be responsible for the sudden increase in trapping sites for deuterium and the concurrent accumulation of deuterium, both in the form of $\mathrm{D}_{2}$ molecules and $\mathrm{D}$ atoms $[18,19,20]$. This mechanism of the trapping site formation can be also considered for molybdenum. Deuterium molecules are assumed to be formed in the sub-surface layer of polycrystalline Mo in the course of D ion irradiation. Therefore, a dip of the $\mathrm{D}$ concentration in polycrystalline Mo at depths of from 0.1 to $1 \mu \mathrm{m}$ observed after D ion irradiation to a fluence of $5 \times 10^{24} \mathrm{D} / \mathrm{m}^{2}$ (Fig. 1) may be connected with the appearance of the blisters and accompanying development of open porosity and deuterium gas release.

The maximum concentration of deuterium at depths of 1-6 $\mu \mathrm{m}$ in the polycrystalline Mo is significantly higher than that in the Mo single crystal (Fig. 1). This suggests that the initial structure of the Mo material plays a decisive role in the diffusion into the bulk and stress-induced formation of trapping sites for deuterium. Possibly, the grain boundaries serve as preferential location for the trapping site nucleation.

For the $115 \mathrm{~nm} \mathrm{MoO}_{3} /$ polycrystalline molybdenum sandwich irradiated with $\mathrm{D}$ ions, the structural modification caused presumably by plastic deformation occurs mainly within the oxide layer and does not penetrate into the Mo bulk. The maximum D concentration of about $10^{-2}$ at.\% found in the metal matrix (beyond the oxide-metal interface) is thought to represent the concentration of deuterium trapped at intrinsic defects in the bulk of polycrystalline Mo at $T_{\text {irr }}=323 \mathrm{~K}$ (Fig. 3).

\section{Conclusions}


Depth profiles of deuterium trapped in Mo single crystal, polycrystalline Mo, and molybdenum trioxide film/polycrystalline Mo sandwich irradiated with $200 \mathrm{eV} \mathrm{D}$ ions have been obtained using the $\mathrm{D}\left({ }^{3} \mathrm{He}, \mathrm{p}\right){ }^{4} \mathrm{He}$ nuclear reaction, analyzing both the $\alpha$ particles and protons. To determine the $\mathrm{D}$ concentration at depths up to $8 \mu \mathrm{m}$, an analyzing beam of ${ }^{3} \mathrm{He}$ ions with energies from 0.69 to $4.0 \mathrm{MeV}$ was used.

Retention in Mo irradiated with low-energy D ions depends strongly on the material structure. While for single crystal and polycrystalline Mo the surface concentrations develop similarly, the penetration into the bulk is much more pronounced in the polycrystalline material. This may be due to enhanced diffusion and trapping along grain boundaries and/or to enhanced stress-induced trap formation of trap sites. The maximum D concentration in the molybdenum trioxide film differs little in value from that for polycrystalline Mo. Blister formation at high fluences is observed for polycrystalline Mo and molybdenum trioxide film, but not for single crystal Mo.

The fluence dependences of $\mathrm{D}$ retention in polycrystalline Mo and $\mathrm{W}$ at $T_{\text {irr }}=323 \mathrm{~K}$ are similar, whereas the dependences of the $\mathrm{D}$ retention on temperature differ somewhat for the two elements.

$\mathrm{D}$ ion irradiation with ion energies well below the displacement threshold modifies the matrix structure to depths of up to about 2 and $8 \mu \mathrm{m}$ in single crystal and polycrystalline Mo, respectively. Plastic deformation of the Mo matrix caused by deuterium super-saturation within the near-surface layer is considered for the formation of trapping sites for deuterium.

\section{Acknowledgements}

We express our appreciation to J. Dorner and M. Fußeder for their technical assistance with the ${ }^{3} \mathrm{He}$ beam analyses, F. Koch for magnetron sputter deposition of the molybdenum oxide film. One of us, V. Alimov, gratefully acknowledges financial support from the Max-Planck-Institut für Plasmaphysik and is candidly indebted to his colleagues from the Bereich Materialforschung for their warm hospitality during his stay in Garching. 


\section{Figure captions}

Figure 1. Depth profiles of deuterium trapped in (a) single crystal Mo and (b) polycrystalline Mo, both irradiated with $200 \mathrm{eV} \mathrm{D}$ ions at $T_{\text {irr }}=323 \mathrm{~K}$ to various fluences.

Figure 2. Blisters formed during irradiation with $200 \mathrm{eV} \mathrm{D}$ ions at $T_{\text {irr }}=323 \mathrm{~K}$ : (a) polycrystalline Mo with fluence of $5 \times 10^{24} \mathrm{D} / \mathrm{m}^{2}$, and (b) $\mathrm{MoO}_{3} /$ polycrystalline Mo sandwich with fluence of $5 \times 10^{22} \mathrm{D} / \mathrm{m}^{2}$. The surfaces were analysed by a SEM at a tilt angle of 70 degrees.

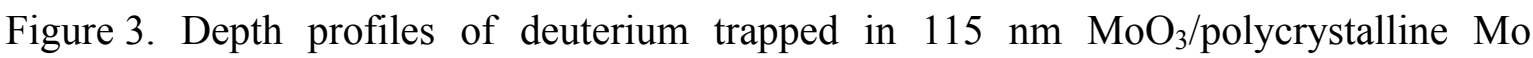
sandwich irradiated with $200 \mathrm{eV} \mathrm{D}$ ions at $T_{\text {irr }}=323 \mathrm{~K}$. Variation of the oxide film thickness due to the $\mathrm{D}$ ion irradiation is shown in the insert.

Figure 4. Depth profiles of deuterium trapped in polycrystalline Mo irradiated with $200 \mathrm{eV}$ $\mathrm{D}$ ions at various temperatures to a fluence of $5 \times 10^{24} \mathrm{D} / \mathrm{m}^{2}$.

Figure 5. (i) Fluence dependence of D retention in single crystal Mo, polycrystalline Mo, and $115 \mathrm{~nm} \mathrm{MoO} /$ polycrystalline Mo sandwich irradiated with $200 \mathrm{eV} \mathrm{D}$ ions at $323 \mathrm{~K}$. (ii) Temperature dependence of D retention in polycrystalline Mo irradiated with $200 \mathrm{eV} \mathrm{D}$ ions to a fluence of $5 \times 10^{24} \mathrm{D} / \mathrm{m}^{2}$. For comparison, the fluence and temperature dependences of D retention in polycrystalline $\mathrm{W}$ [19] are also shown. The deuterium retention in the Mo and $\mathrm{W}$ samples was calculated from deuterium depth profiles measured up to a depth of $8 \mu \mathrm{m}$. 


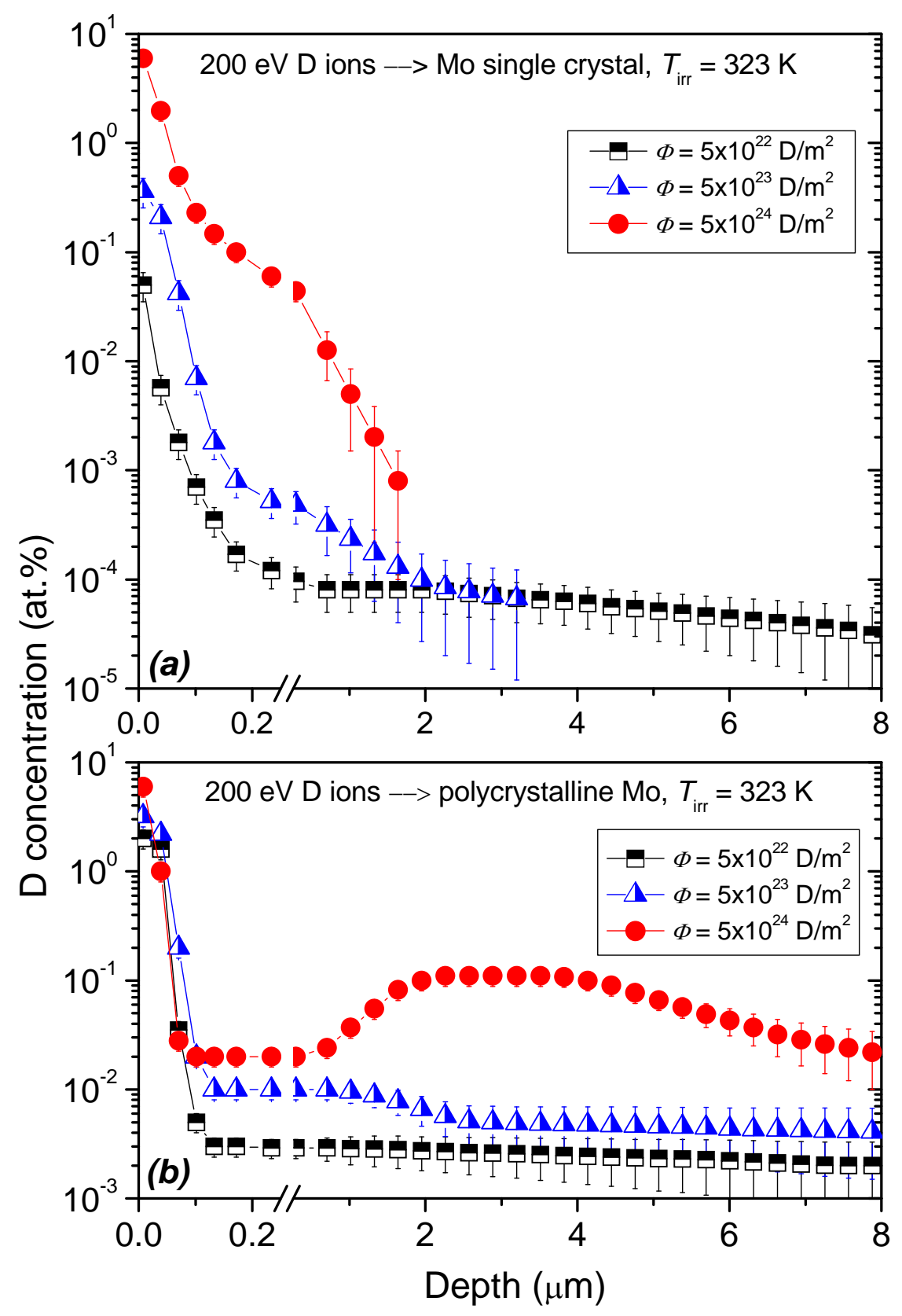

Figure 1. Depth profiles of deuterium trapped in (a) single crystal Mo and (b) polycrystalline Mo, both irradiated with $200 \mathrm{eV}$ D ions at $T_{\text {irr }}=323 \mathrm{~K}$ to various fluences. 


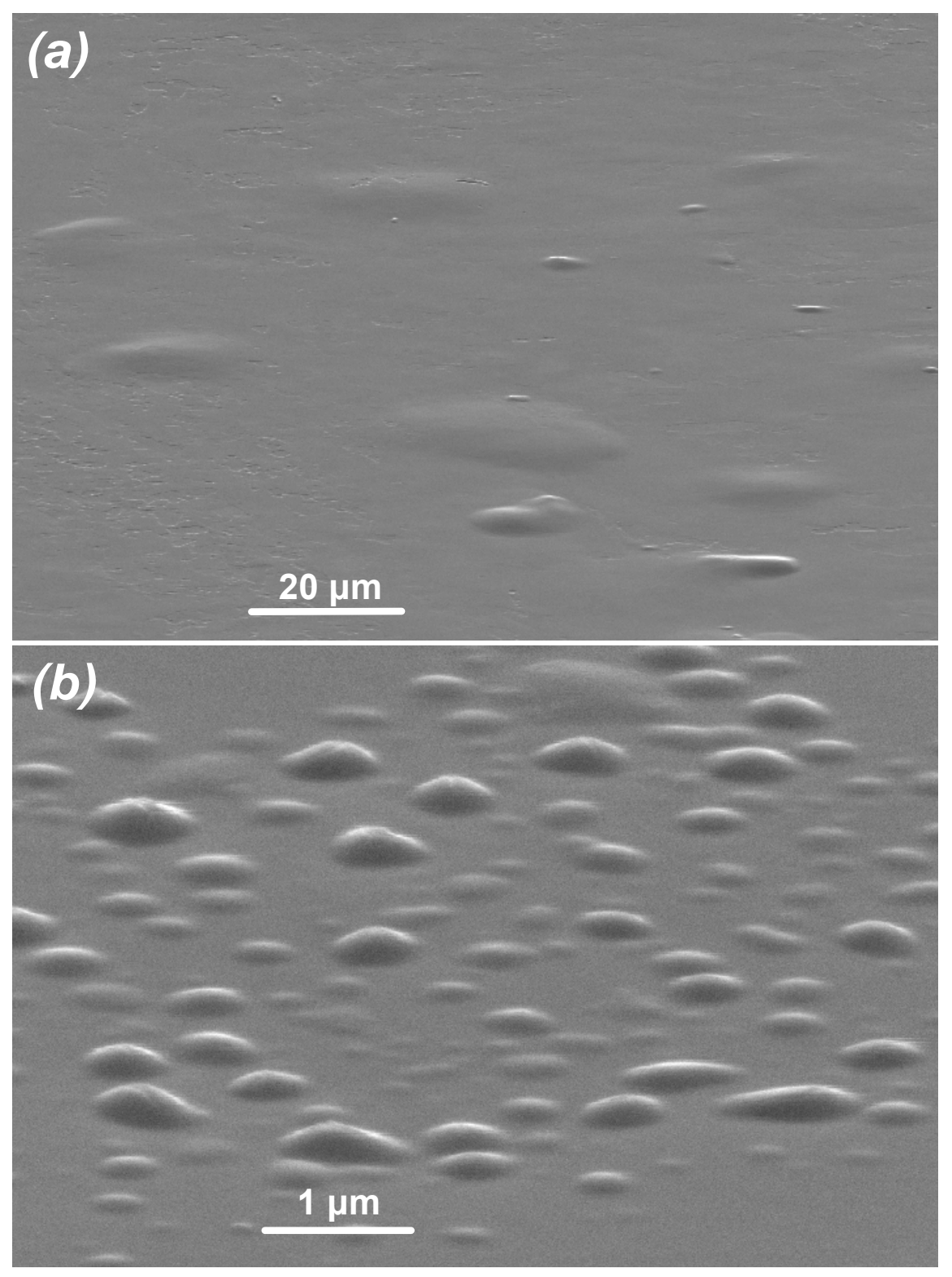

Figure 2. Blisters formed during irradiation with $200 \mathrm{eV} \mathrm{D}$ ions at $T_{\text {irr }}=323 \mathrm{~K}$ : (a) polycrystalline Mo with fluence of $5 \times 10^{24} \mathrm{D} / \mathrm{m}^{2}$, and (b) $\mathrm{MoO}_{3} /$ polycrystalline $\mathrm{Mo}$ sandwich with fluence of $5 \times 10^{22} \mathrm{D} / \mathrm{m}^{2}$. The surfaces were analysed by a SEM at a tilt angle of 70 degrees. 


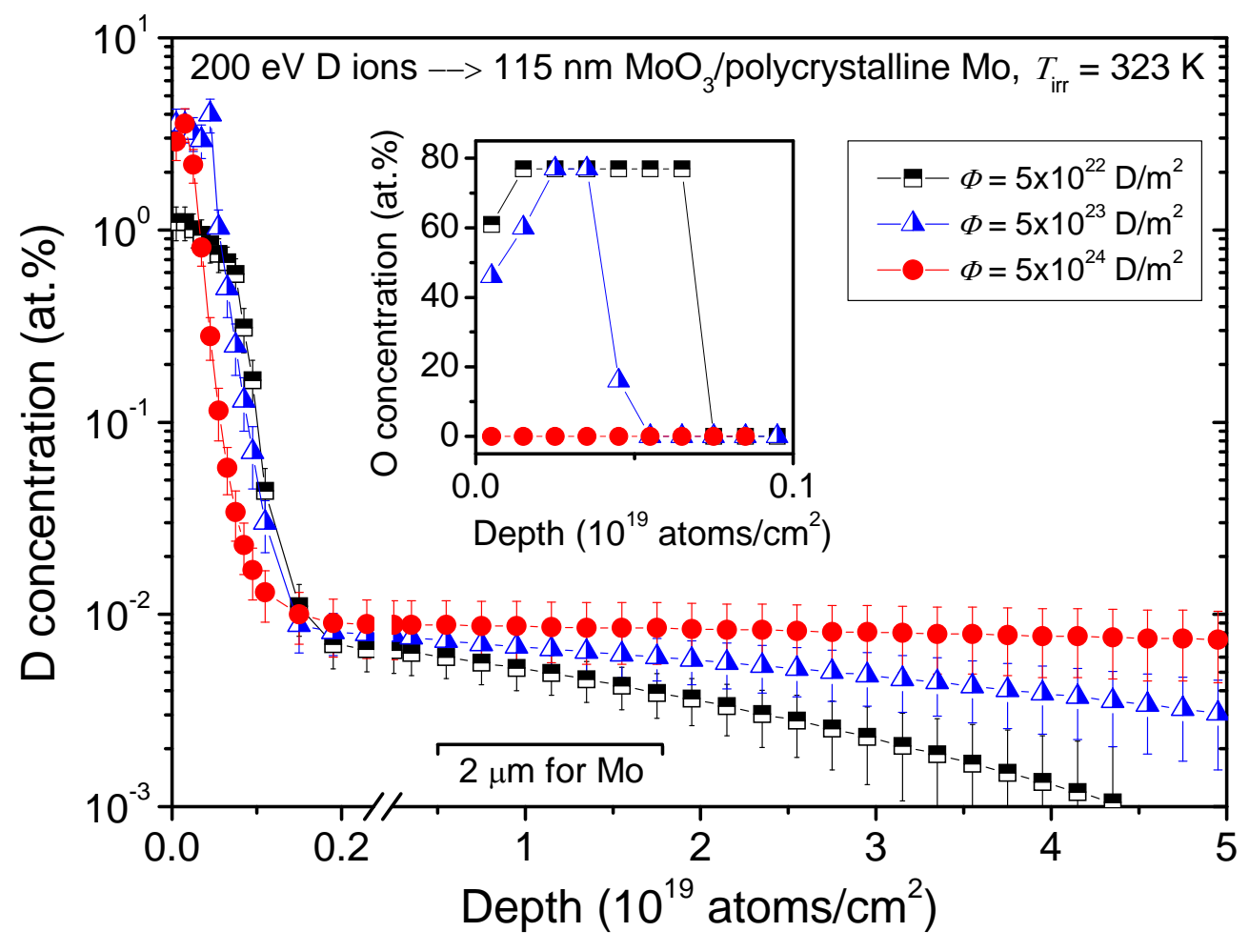

Figure 3. Depth profiles of deuterium trapped in $115 \mathrm{~nm} \mathrm{MoO}_{3} /$ polycrystalline $\mathrm{Mo}$ sandwich irradiated with $200 \mathrm{eV} \mathrm{D}$ ions at $T_{\text {irr }}=323 \mathrm{~K}$. Variation of the oxide film thickness due to the $\mathrm{D}$ ion irradiation is shown in the insert. 


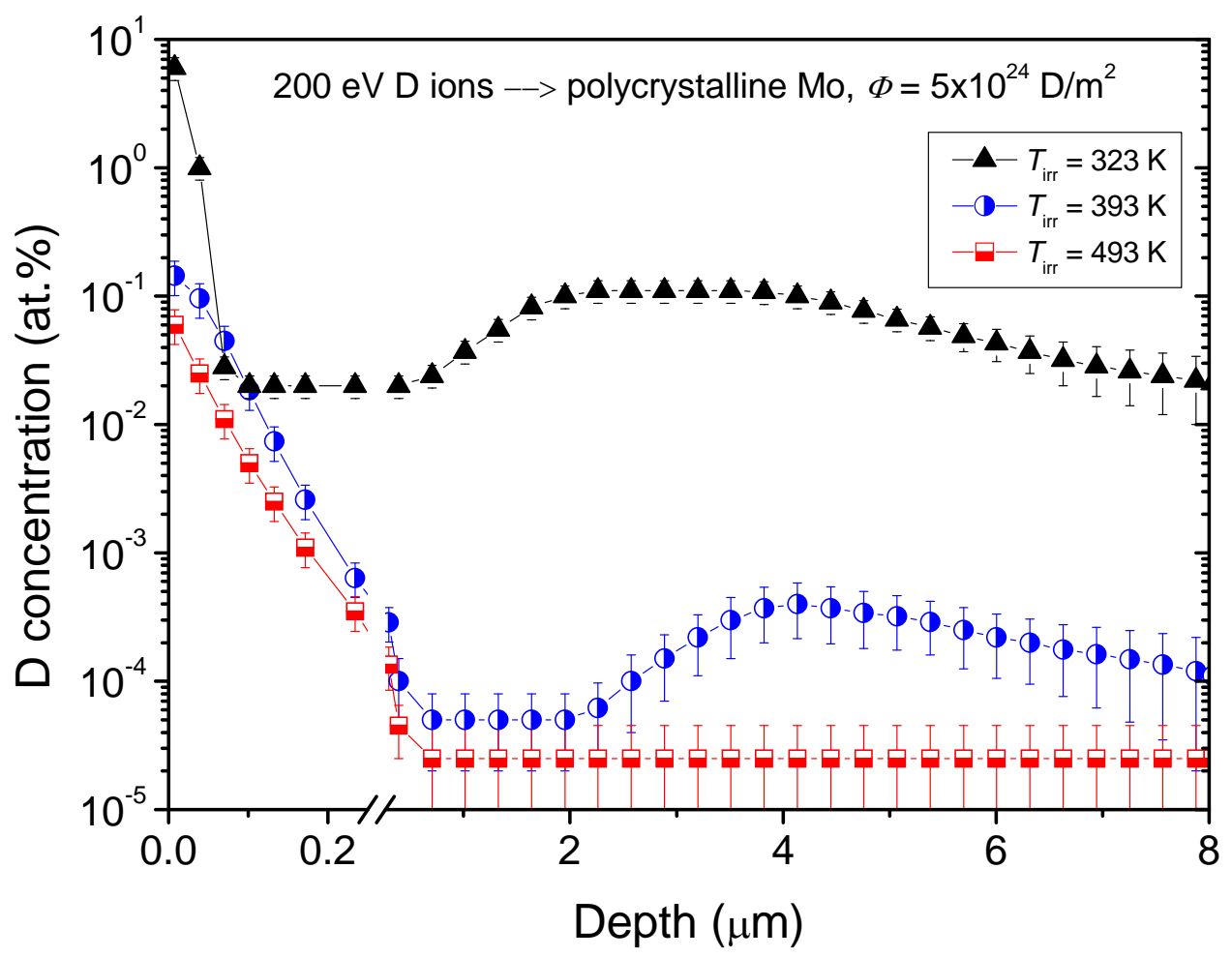

Figure 4. Depth profiles of deuterium trapped in polycrystalline Mo irradiated with $200 \mathrm{eV}$ D ions at various temperatures to a fluence of $5 \times 10^{24} \mathrm{D} / \mathrm{m}^{2}$. 


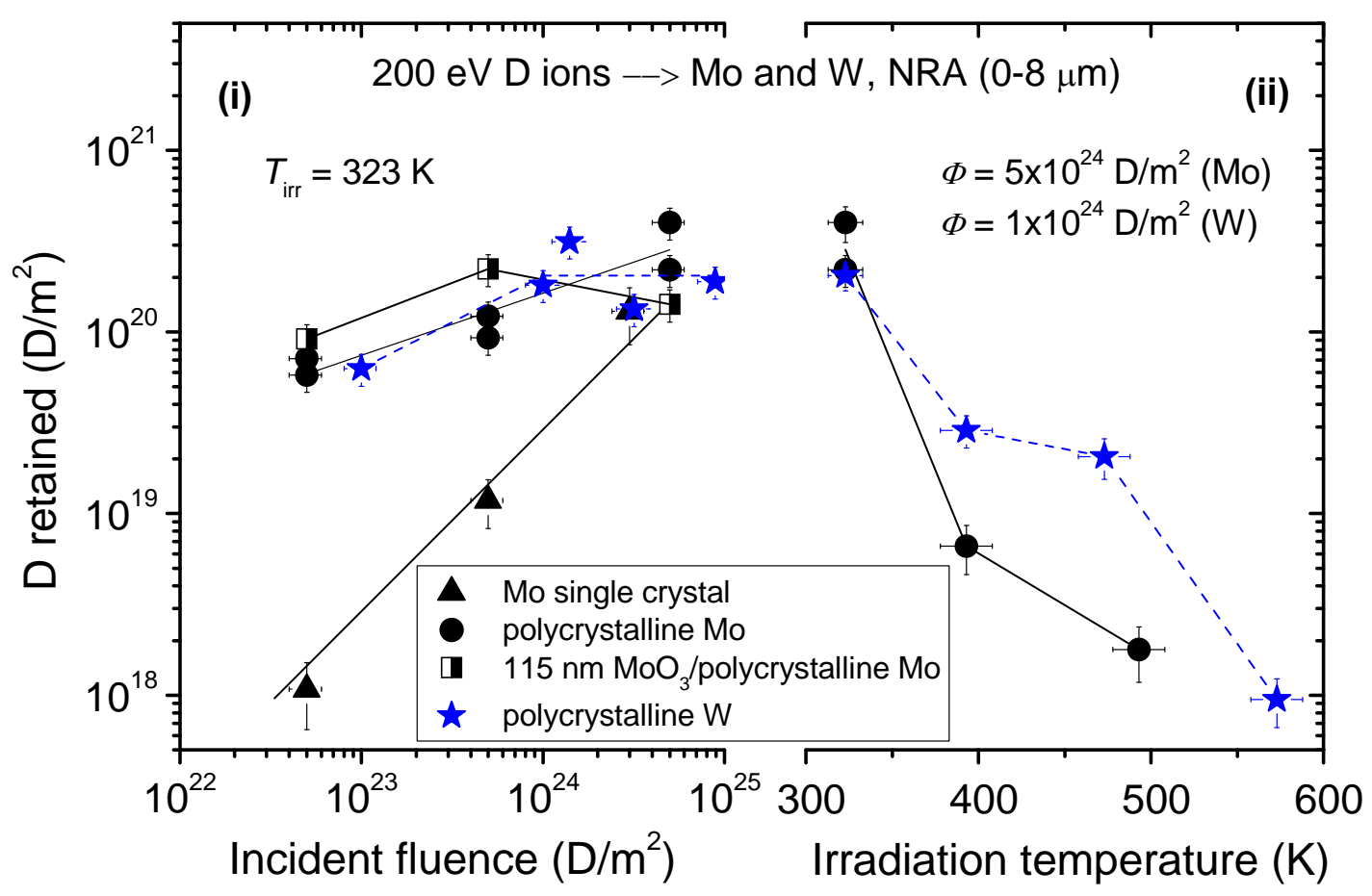

Figure 5. (i) Fluence dependence of D retention in single crystal Mo, polycrystalline Mo, and $115 \mathrm{~nm} \mathrm{MoO} /$ polycrystalline Mo sandwich irradiated with $200 \mathrm{eV}$ D ions at $323 \mathrm{~K}$. (ii) Temperature dependence of $\mathrm{D}$ retention in polycrystalline Mo irradiated with $200 \mathrm{eV} \mathrm{D}$ ions to a fluence of $5 \times 10^{24} \mathrm{D} / \mathrm{m}^{2}$. For comparison, the fluence and temperature dependences of D retention in polycrystalline W [19] are also shown. The deuterium retention in the Mo and $\mathrm{W}$ samples was calculated from deuterium depth profiles measured up to a depth of $8 \mu \mathrm{m}$. 


\section{References}

[1] S.J. Wukitch, B. Lipschultz, E. Marmar, Y. Lin, A. Parisot, M. Reinke, J. Rice, J. Terry, J. Nucl. Mater. 363-365 (2007) 491.

[2] A. Litnovsky, P. Wienhold, V. Philipps et al., J. Nucl. Mater. 363-365 (2007) 1395.

[3] H. Zushi, K. Nakamura, K. Hanada et al., Nucl. Fus. 45 (2005) S142.

[4] R. Schulz, R. Behrisch, B.M.U. Scherzer, J. Nucl. Mater. $93 \& 94$ (1980) 608.

[5] R. Schulz, R. Behrisch, B.M.U. Scherzer, Nucl. Instr. and Meth. 168 (1980) 295.

[6] R. Sakamoto, T. Muroga, N. Yoshida, J. Nucl. Mater. 233-237(1996) 776.

[7] A.A. Haasz, J.W. Davis, J. Nucl. Mater. 241-243 (1997) 1076.

[8] H. Yanagihara, Y. Yamauchi, T. Hino, Y. Hirohata, T. Yamashina, J. Nucl. Mater. 241243 (1997) 1098.

[9] R. Yamaguchi, M. Okada, O. Onoue, F. Ono, M. Yamawaki, J. Nucl. Mater. 258-263 (1998) 1104.

[10] S. Nagata, K. Takahiro, J. Nucl. Mater. 283-287 (2000) 1038.

[11] T.Hirai, T. Fujiwara, K. Tokunaga, N. Yoshida, A. Komori, O. Motojima, S. Itoh, TRIAM group, J. Nucl. Mater. 283-287 (2000) 1177.

[12] M. Miyamoto, T. Hirai, K. Tokunaga, T. Fujiwara, N. Yoshida, J. Nucl. Mater. 307$311(2002) 710$.

[13] R.A. Causey, C.L. Kunz, D.F. Cowgill, J. Nucl. Mater. 337-339 (2005) 600.

[14] G.M. Wright, D.G. Whyte, B. Lipschultz, R.P. Doerner, J.G. Kulpin, J. Nucl. Mater. (2007).

[15] W. Eckstein, C. García-Rosales, J. Roth, W. Ottenberger, Sputtering Data, Tech. Rep. IPP 9/82, Max-Planck-Institut für Plasmaphysik, Garching, 1993.

[16] M. Mayer, SIMNRA User's Guide, Tech. Rep. IPP 9/113, Garching, 1997, and www.rzg.mpg.de/ mam.

[17] V.Kh. Alimov, M. Mayer, J. Roth, Nucl. Instr. and Meth. B 234 (2005) 169.

[18] V.Kh. Alimov, J. Roth, M. Mayer, J. Nucl. Mater. 337-339 (2005) 619.

[19] V.Kh. Alimov, J. Roth, Physica Scripta, T128 (2007) 6.

[20] A.A. Haasz, M. Poon, J. Davis, J. Nucl. Mater. 266-269 (1999) 520. 